\title{
MUNICIPIOS Y GOBIERNO ABIERTO, MÁS ALLÁ DEL GOBIERNO ELECTRÓNICO
}

\author{
Christian Cruz Meléndez* \\ Ayesha Zamudio VÁzQuez ${ }^{* *}$
}

\section{Resumen}

El propósito de este artículo es analizar al gobierno electrónico y al gobierno abierto como herramientas para el fortalecimiento de los municipios. Se hace un análisis conceptual de ambos términos, para comprender a qué nos referimos y por qué se proponen para beneficio de los gobiernos municipales; también se revisa la evolución que ambos han tenido en México, $y$, por último, qué hay en los gobiernos municipales sobre estos temas, y cómo contribuyen a que el municipio asuma sus responsabilidades, como la institución de gobierno más cercana a la población.

Palabras clave: gobierno electrónico, gobierno abierto, municipios.

\section{OPEN GOVERNMENT AND MUNICIPALITIES: BEYOND E-GOVERNEMENT}

\begin{abstract}
This article's purpose is to analyze egovernment and open government as tools to strengthen the role of municipal government. It reviews the evolution of both tools in Mexico and contains a conceptual analysis of both terms to gain an understanding of their meaning and of the reason why they are promoted for the benefit of local governments. Finally, it explores the availability of these tools in the municipalities, and how they contribute
\end{abstract}

* Doctor en Ciencias Políticas y Sociales, orientación en Administración Pública. Catedrático CONACYT-Unsis, División de estudios de Posgrado, Estado de México (México). [acm_christian@yahoo.com.mx].

** Maestra en Administración Pública. Subdirectora de área, Procuraduría General de la República, Ciudad de México (México). [ayesha.zamudio@gmail.com].

Recibido: 30/01/2017/ Modificado: 13/04/2017/ Aceptado: 01/06/2017.

Para citar este artículo

Cruz Meléndez, C. y Zamudio Vázquez, A. (2017). Municipios y Gobierno abierto, más allá del Gobierno electrónico. OPERA, 21, pp. 55-77.

DOI: https://doi.org/10.18601/16578651.n21.04 
to each municipality in the fulfillment of its responsibilities.

Key words: E-government, open government, local governments.

\section{INTRODUCCIÓN}

La mejora de la administración pública es una necesidad cada vez más apremiante. Aun cuando estas no sean las ideales, o los esfuerzos sean mínimos, en la retórica de casi cualquier gobernante se encuentran promesas de cambios al aparato gubernamental, llamados mejora, innovación o modernización, aunque en la práctica estas ideas han "quedado subordinadas a otros objetivos: por un lado, a las políticas de desarrollo económico e industrial y, por el otro, a los imperativos del control político, resultado de las prácticas de un Estado autoritario” (Pardo, 2007, p. 895).

El proceso de reforma de la administración pública se agudizó en la década de los ochenta, con el quiebre del Estado benefactor, el cual fue tildado de grande, obeso, hipertrofiado, interventor, propietario, dirigista, sobreregulador (Aguilar, 2009). Los modelos administrativos basados en el modelo burocrático de Max Weber estaban rebasados y fueron criticados por su buropatología, que influía "la priorización de los medios sobre los fines, la desconsideración de clientes y usuarios, las diversas manifestaciones de alienación de los trabajadores (desmotivación, absentismo y rotación excesiva, chapuzas, conflictividad costosa y estéril...), a lo que se suele responder con más control” (Pratts, 2005, p. 112).
Ante ello surgió un nuevo modelo de trabajo basado en conocimientos y prácticas administrativas empresariales, un kit de herramientas que permitiría enmendar las fallas del esquema burocrático conocido como la nueva gestión pública (NGP). Dichas prácticas forman parte de un modelo de trabajo posburocrático, y se clasifican en categorías como "modernización, reingeniería, reestructuración, innovación, rediseño $[y]$ reinvención, que apuntan a la transformación de las organizaciones públicas, en cuanto a normas, estructuras y patrones directivos y organizacionales" (Aguilar, 2009, p. 146).

La NGP incluye el uso de la tecnología en la administración pública. Es natural, por tanto, que surjan propuestas que alienten su uso para incrementar la eficiencia, la eficacia y la calidad de los servicios públicos. Surge así el gobierno electrónico (GE). De él se espera que "pueda aportar beneficios potenciales a la reorganización de las estrategias internas en el sector público. Basándose en las experiencias del sector privado, las TIC se perciben como una herramienta poderosa para organizar y reorganizar los procedimientos de la organización” (Cordella, 2007, p. 269).

Sin embargo, la NGP ha generado expectativas que han sido difíciles de alcanzar, en vista de que la opacidad del Gobierno no "aporta información suficiente para configurar adecuadamente el voto, se apodera de lo público y lo gubernamentaliza en el mejor de los casos o lo patrimonializa en el peor, no rinde cuentas no se somete realmente al derecho, y traiciona la soberanía popular y la igualdad política” (Ramírez-Alujas, 2011, p. 105). De ahí 
que valores como transparencia, rendición de cuentas y participación ciudadana se retoman bajo la óptica de gobierno abierto.

En este artículo nos enfocaremos en el gobierno electrónico y gobierno abierto, como elementos del proceso de reforma en la administración pública, al tomar en común el uso de las tecnologías de la información y comunicación (TIC). Puntualizamos esta temática en los municipios, dado que son la instancia de gobierno más cercana a la sociedad, "de su seno, de las necesidades, reclamos y alternativas de solución planteadas por la comunidad deben emanar las políticas que orienten e impulsen el crecimiento nacional” (Mejía, 2013, p. 145). Por ello es necesario entender el vínculo entre tales temas con los municipios, a efecto de dotar al gobierno con mejores herramientas que le permitan responder a los intereses ciudadanos, así como disminuir los altos niveles de impunidad y corrupción que actualmente enfrenta nuestro país.

\section{CONCEPTOS Y TEORÍA DEL GOBIERNO ELECTRÓNICO Y GOBIERNO ABIERTO}

Gobierno electrónico (GE) y gobierno abierto (GA) son dos conceptos que actualmente gobiernos y ciudadanía perciben como sinónimos, empero son distintos. Cada uno tiene su esfera de trabajo, aun cuando comparten objetivos comunes, e incluso simultáneos. El gobierno electrónico (e-gobierno) es

...una nueva forma de gobierno que utiliza las Tecnologías de Información y Comunicación (TIC), con modalidades para la gestión, planificación y administración, por medio de portales en Internet con información referente a las dependencias de la administración pública, órganos de gobierno, poderes, legislación de los tres niveles de gobierno, así como servicios y trámites para permitir a la sociedad lograr un mayor contacto con la administración pública. (Pérez, Camacho, Mena y Arroyo, 2015-2016).

Si bien la tecnología tiene una larga historia en la administración pública, en un principio fungió como apoyo para asuntos administrativos, limitada a computadoras y otro tipo de instrumentos técnicos, centrados en procesos de automatización (Criado, 2009), lo que se llegó a conocer como informatización. De acuerdo con Gil y Luna (2008), es posible identificar cuatro periodos del uso de las tecnologías de información y comunicación (TIC) en la administración pública:

1. En la década de los cincuenta se inicia la introducción de computadoras y la automatización de tareas, con instrumentos informáticos.

2. En las décadas de los sesenta y setenta, la administración pública empezó a utilizar computadoras centrales.

3. Para los años ochenta y noventa se incorporaron computadoras personales e iniciaron programas de capacitación al personal en materia informática.

4. Desde los años noventa hasta el día de hoy la administración pública se sumó al boom del internet, la interoperabilidad, la telefonía móvil y las redes sociales. Es a partir de este momento que se utiliza el término gobierno electrónico. 
El año de 1999 se considera formalmente, entre los estudiosos del tema, como el del surgimiento del término GE, también conocido como gobierno digital. La paternidad de dicho término se le atribuye al entonces vicepresidente de los Estados Unidos Al Gore (1999), cuando envía el memorando e-government directive, solicitando a las dependencias gubernamentales aplicar la tecnología, señalando que "si se utiliza de forma creativa la tecnología de Internet y la información, pueden ser una herramienta de gran alcance para hacer frente a algunos de nuestros más difíciles problemas sociales".

En el sentido más amplio, el gobierno electrónico implica el uso o incorporación de las Tic dentro de la administración pública. Sin embargo, habría que acotar que si bien la apreciación es correcta, no refleja su trascendencia para el aparato gubernamental. En una época en donde la información es compartida y comunicada con tan alta velocidad como en ninguna otra, y "dado el enorme crecimiento de las transacciones electrónicas en el sector privado, es entendible que los ciudadanos comparen el desempeño de los gobiernos locales al de gigantes comerciales como Amazon.com, [...] por lo que el cambio en su expectativa y percepción es inevitable" (Streib y Willoughby, 2002). El intensivo uso del internet y otras tecnologías impulsan y ayudan a los ciudadanos a comunicar más sobre su insatisfacción, a exigir al gobierno y también, a participar de manera activa en las políticas públicas.

El ranking de gobierno electrónico (GE) publicado bianualmente por la Organización de las Naciones Unidas (ONU) se compone de tres elementos: 1) disponibilidad de servicios en línea, 2) infraestructura de telecomunica- ciones y 3) capacidad humana. Los resultados del ranking indican que México ha perdido posiciones. En 2008, nuestro país se ubicaba en el lugar 31, cayendo al lugar 56 en 2010 y al 63 en 2014; con una ligera recuperación en 2016 tras subir al lugar 59. Las causas de la caída entre el ańo 2010 y el 2014 se debieron a la brecha digital, una deficiente infraestructura en materia de telecomunicaciones, altos precios y la poca oferta de servicios transaccionales en línea. En 2016, la recuperación en el ranking fue el resultado de la publicación de la Ley Federal de Telecomunicaciones y Radiodifusión del 14 de julio de 2014, ya que esta dio certeza al marco legal de la infraestructura de telecomunicaciones.

Últimamente, el concepto de abierto (openness) ha tomado fuerza en el ámbito político, empero filósofos como Karl Popper ubican sus orígenes en la Atenas democrática del siglo quinto a. C. Sin embargo, dicho concepto solo cobró relevancia social luego de que Popper escribiera la Sociedad abierta y sus enemigos, durante su exilio en Nueva Zelanda a causa de la Segunda Guerra Mundial. En él expone una amplia crítica histórica al pensamiento y las políticas rígidas basadas en verdades inmutables, calificándolas con el término de sociedades cerradas puesto que en ellas la voluntad del individuo se encuentra sometida. En contraposición, la sociedad abierta se basa en principios democráticos que permiten a un individuo confrontar sus decisiones personales, en un programa político de equidad individual (Popper, 1962, pp. 169-201). Así, mientras los individuos en sociedades cerradas ven limitado su poder de decisión, la sociedad abierta impulsa procesos de cooperación y participación 
social. Esta propuesta sienta las bases de lo que hoy en día se conoce como gobierno abierto

De acuerdo con Nathaniel Tkacz (2013), el (re)surgimiento y la (re)articulación del concepto de abierto (openness) tuvo lugar en las culturas del software. En su artículo "From open source to open government: A critique of open politics", Tkacz nos ofrece un recuento de este proceso.

En 1980, Richard Stallman, programador en aquella época en el AI Lab del MIT, al intentar hacer ligeras modificaciones al software de una impresora Xerox, se enfrentó con la negativa de la empresa a entregarle el código fuente que le permitieran reconfigurar la máquina. Este suceso provocó en Stallman frustración sobre los procesos de mercantilismo del software y comenzó el Movimiento de Liberalización del Software (FSM, por sus siglas en inglés) para el libre uso de software por cualquier persona. Sin embargo el movimiento, si bien innovador, no tuvo eco dado que no abonaba a los objetivos del libre mercado. Casi dos décadas después, en 1998, Eric Raymond, junto con programadores de alto nivel como Linus Torvalds, creador de Linux, optaron por el desarrollo de sistemas tecnológicos de participación abierta y comunitaria, lo que dio lugar a la Iniciativa de Código Abierto (osi, por sus siglas en inglés). En clara contraposición al FSM, el osi no rivaliza con la idea de propiedad y ganancia de un producto, por el contrario, la alienta bajo supuestos de eficiencia y libre mercado. Fue así que el concepto de abierto comenzó su articulación alrededor de las nociones de participación, colaboración y transparencia.

Las propuestas del código abierto pronto cautivaron las mentes de otras esferas sociales, como la política y las instituciones gubernamentales. Lo que dio lugar a la noción de gobierno abierto, un concepto impregnado por la cultura del software aplicable a la administración pública. A la luz de este fenómeno, autores como Rodrigo Sandoval (2013) definen al gobierno abierto como una plataforma tecnológica que utiliza las herramientas de información y comunicación a su alcance para desempeñar su cometido. En efecto, la más reciente ola que (re)toma el concepto de Gobierno Abierto se alberga en la iniciativa lanzada por el presidente de Estados Unidos Barack Obama, en enero del 2009, mediante el Memorándum de Transparencia y Gobierno Abierto.

Este comunicado urgía a su administración a abrir la información del Gobierno haciéndola pública y fija como objetivo, a trabajar bajo el principio de máxima publicidad señalando los tres pilares básicos de este concepto:

- Transparencia (saber).

- Participación (tomar parte).

- Colaboración (contribuir).

La Carta Iberoamericana de Gobierno Abierto (2016), impulsada por el Centro Latinoamericano de Administración para el Desarrollo, agrega la rendición de cuentas como un cuarto pilar. Pero ¿es el GA realmente un paradigma? En teoría la respuesta es sí, pues hacia allá debe caminar la administración pública; en la práctica, el proceso se encuentra en una etapa inicial. Para los países en desarrollo el GA alberga la promesa de transformación de gobiernos autoritarios y permeados por una cultura de opacidad, que impide a los ciudadanos 
"conocer la información público-gubernamental para evaluar tipos de desempeño, la calidad de la acción institucional y el modo de obrar de los políticos y los administradores del Estado" (Uvalle, 2009, p. 85).

Los movimientos sociales, junto con un cambio de expectativas, como Streib y Willoughby proponen, han generado "un nuevo tipo de ciudadano: uno que es más crítico, organizado y activo, una persona que espera una mayor participación en la toma de decisiones políticas y que está interesado en colaborar con el gobierno para buscar soluciones a los problemas y necesidades de la comunidad" (Ramírez y Dassen, 2014, p. 1), y que en las TIC ha encontrado un gran aliado.

En 2011, México se sumó a la Alianza por el Gobierno Abierto (AGA), y a la fecha se han realizado tres planes de acción, siendo el vigente el del 2016-2018 con 26 compromisos. El Comité Directivo Internacional de la Alianza del Gobierno Abierto lanzó en el año 2015 la Declaración sobre Gobierno Abierto para la implementación de la Agenda 2030 para el Desarrollo Sostenible. Su objetivo es hacer que las acciones en materia de apertura gubernamental contribuyan a la implementación del desarrollo sostenible a través de una participación activa de los ciudadanos (Alianza para el Gobierno Abierto, 2017).

Durante el periodo 2014-2016, México fungió como presidente de la Alianza por el Gobierno Abierto. Sin embargo, las métricas oficiales en la materia se contraponen. De acuerdo con el Índice de Percepción de la Corrupción 2014, realizado por Transparencia Internacional, México ocupa el lugar 103 de 175 países, por lo que se considera reprobado en el combate a la corrupción. Lo que es más, tiene la calificación más baja de los 34 países que forman la Organización para la Cooperación y Desarrollo Económico (OCDE). En un esfuerzo por revertir estos indicadores el país ha realizado diversas reformas legislativas para optimizar el marco normativo del combate a la corrupción; empero, las modificaciones no han alcanzado para mejorar la percepción ciudadana en el tema, y en 2016 México retrocedió cinco posiciones en el índice respecto al 2015, convirtiéndose de esta manera en el país que más retrocedió en la región de las Américas.

\section{BENEFICIOS Y RELACIÓN DEL GOBIERNO ELECTRÓNICO Y EL GOBIERNO ABIERTO}

En el gobierno electrónico las herramientas tecnológicas que lo hacen posible, como sitios web, aplicaciones móviles, redes sociales y dispositivos móviles, entre otros, contribuyen a alcanzar múltiples objetivos gubernamentales como aumentar la eficiencia, la eficacia y la calidad en la atención del servicio público. Los efectos benéficos se traducen en eliminación de papeleos, romper con las barreras burocráticas de lugares y horarios (servicios 24/7), aumento de los ingresos públicos o disminución del gasto corriente.

El argumento de Popper respecto de la sociedad abierta es isomórfico con los principios de apertura de la cultura computacional (Tkacz, 2012, p. 390). De ahí que exista una tendencia natural a considerar que "un gobierno abierto no podría ocurrir sin la tecnología. Ahora bien es importante no confundir (ni reducir de manera simplista) la nueva idea de 
gobierno abierto al mero uso de las tecnologías o al concepto de gobierno electrónico o e-Administración" (Ramírez, 2012). Ello en vista de que, bajo determinadas circunstancias, es posible prescindir de la tecnología dentro del gobierno abierto.

Gobierno abierto y electrónico se funden en un proceso de complementariedad, una propuesta ya señalada por Oscar Ozlak (2013), quien argumenta que "si consideramos que el GE dirige sus objetivos a la gestión de la administración mientras que el GA propone una nueva forma de vinculación entre gobierno y sociedad estaremos hablando de dos elementos complementarios y que producirán efectos el uno a partir del otro".

El proceso, como abunda el propio Ozlak, entraña una relación de doble vía entre ciudadanía y Estado, posibilitada por la disponibilidad y la aplicación de TIC que facilitan múltiples interacciones entre actores sociales y estatales, y se traducen en vínculos más transparentes, participativos y colaborativos. Bajo esta perspectiva, "el gobierno electrónico y la tecnología han sido factores que ayudan a lograr el objetivo del gobierno abierto, que facilita los fines de este, y que el ciudadano ha encontrado en el gobierno electrónico y las TIC medios que en el pasado no tenía para participar, para hacerse escuchar, incluso por una cuestión de comodidad" (Cruz, 2015).

La participación que impulsan el GE y el GA genera una convergencia de vínculos paralelos (figura 1). Esto se debe a que ambas áreas pueden existir una sin la otra, es decir se puede tener un gobierno electrónico evolucionado, pero seguir siendo opaco y cerrado, y se puede ser abierto aunque la tecnología sea baja o nula. Las herramientas tecnológicas facilitan los logros que el GA pueda alcanzar en términos de transparencia, participación y colaboración ciudadana. Una complementariedad de resultados que el GA obtiene a partir del GE y viceversa.

En torno al quehacer gubernamental las herramientas que son utilizadas con mayor frecuencia en el GE son los sitios web (incluidos los portales de transparencia, datos abiertos y de compras públicas), a los que se han agregado ahora el uso de aplicaciones móviles y redes sociales (Facebook, Twitter). Por su parte, el GA cuenta con herramientas en las que no es

FIGURA 1. CONVERGENCIA GOBIERNO ELECTRÓNICO Y GOBIERNO ABIERTO

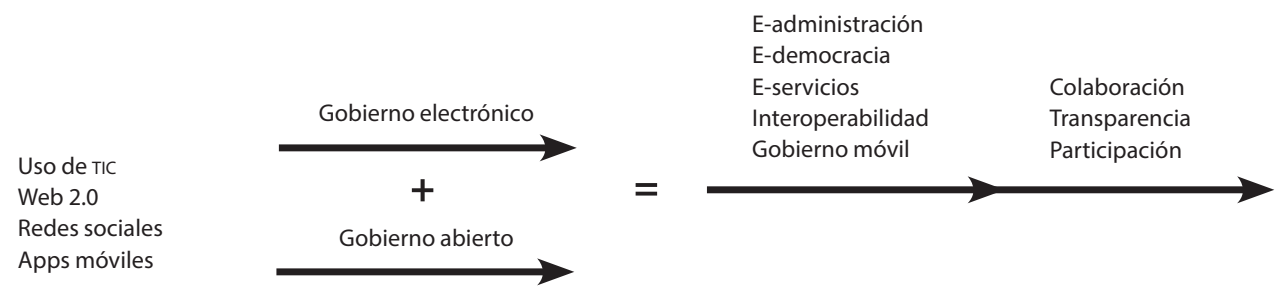

Fuente: elaboración propia. 
indispensable contar con alguna TIC como es el caso del presupuesto participativo, comités ciudadanos, grupos focales, encuestas, jurados de ciudadanos, sondeos, entre otros (tabla 1).

TABLA 1. HERRAMIENTAS DE GOBIERNO ELECTRÓNICO Y DE GOBIERNO ABIERTO CON MAYOR FRECUENCIA DE USO EN EL GOBIERNO

\begin{tabular}{|c|c|}
\hline $\begin{array}{c}\text { Herramientas } \\
\text { gobierno } \\
\text { electrónico }\end{array}$ & Herramientas gobierno abierto \\
\hline $\begin{array}{l}\text { Sitio web } \\
\text { - Portales de } \\
\text { Gobierno }\end{array}$ & $\begin{array}{l}\text { - Portales de transparencia foca- } \\
\text { lizada } \\
\text { - Portales de visualización } \\
\text { - Datos abiertos } \\
\text { - Portales de compras públicas } \\
\text { (considerar del lado de GE) } \\
\text { - Crowdsourcing y citizensourcing } \\
\text { - E-peticiones, campañas y reco- } \\
\text { lección de firmas }\end{array}$ \\
\hline Apps móviles & - Apps cívicas \\
\hline \multirow{3}{*}{$\begin{array}{l}\text { Redes sociales } \\
\text { Facebook, Twitter }\end{array}$} & - Facebook, Twitter \\
\hline & Herramientas no tecnológicas \\
\hline & $\begin{array}{l}\text { - Comités } \\
\text { - Presupuestos participativo } \\
\text { - Leyes de acceso a la informa- } \\
\text { ción } \\
\text { - Foros abiertos } \\
\text { - Comités ciudadanos y toma de } \\
\text { decisiones participativas } \\
\text { - Grupos focales } \\
\text { - Jurado de ciudadanos }\end{array}$ \\
\hline
\end{tabular}

Fuente: elaboración propia con información del Catálogo de Herramientas de GA de la OEA aplicables en América.

Un aspecto relevante por considerar en esta relación de doble vía es la evolución del gobierno electrónico. Un portal insuficientemente desarrollado abona muy poco al GE.
Existe un modelo de estudio de portales web llamado evolutivo, que parte "del supuesto de que el gobierno electrónico en general y consecuentemente los portales [...], en particular, están en constante evolución; mejorando paulatinamente y agregando sofisticación tecnológica y organizacional" (Gil-García, 2014, p. 88). Las etapas de este modelo son: presencia, interacción, transacción, integración y participación, en este caso intercambiada por el concepto de gobierno abierto, cuando el portal permite la participación, la colaboración y la transparencia. Así, entre mayor evolución exista en un sitio web, mayor será la contribución al GA. Para el ciudadano, tal proceso se traduce en un incremento en el volumen de la información difundida, herramientas de pago de servicios en línea o el realizar trámites gubernamentales completamente a través de internet. En la tercera parte de este artículo el modelo será desarrollado a profundidad.

La activa y estrecha interacción que tienen el GE y el GA constantemente los entrelaza, llegando incluso a confundirlos. Es decir, algunos gobiernos ven el uso de las TIC, y por tanto la implementación de un GE, como una forma de apertura gubernamental y han plasmado tal propuesta como parte de los compromisos y las metas de los planes de acción nacionales de la alianza por el gobierno abierto ${ }^{1}$. Esto significa que las administraciones consideran la inclusión de tecnología como una estrategia de apertura gubernamental, sin que ello implique un aumento de la transparencia. De ahí la importancia de hacer esta distinción clara

1 Si se revisan los compromisos de México sobre gobierno abierto, la mayoría de ellos tienen como producto final un sitio web o incluyen un elemento tecnológico, http://tablero.gobabiertomx.org/\#. Es decir, se entregaron productos de gobierno electrónico. 
y fundamental entre el uso de herramientas de tecnología de la información para mejorar un Gobierno, y la apertura gubernamental que provoca la transparencia y la rendición de cuentas.

\section{DESARROLLO DEL GOBIERNO ELECTRÓNICO Y EL GOBIERNO ABIERTO EN MÉXICO}

Desde su constitución como país independiente, México desarrolló una cultura tanto gubernamental como administrativa vertical, autoritaria y cerrada, caracterizada por el

...presidencialismo centralista y la existencia de un partido-Estado que controlaba los sectores social, privado y gubernamental en los niveles Federal, estatal y municipal. La dictadura perfecta recaía en el poder absoluto del presidente de la República, quien por medio del partido-Estado, controlaba a los poderes Judicial y Legislativo, y a los gobernadores de las 31 entidades federativas (Hevia de la Jara, 2013).

En esta, los gobernantes no rendían cuentas respecto de sus actividades, utilizaban recursos públicos discrecionalmente y trabajaban con un exceso de sigilo a fin de mantener la información generada en las dependencias.

En 1994 surge el primer sitio web del Gobierno de México, mismo que perteneció a la Presidencia de la República. Fue durante el sexenio 1994-2000 que se incorpora la tecnología a los procesos de modernización administrativa, bajo el nombre de procesos de informatización, creando el sistema de compras públicas por internet Compranet. En el año 2000 comienza a utilizarse el término gobierno digital, y surgen las primeras estrategias de alfabetización digital (sistema e-México), así como el primer documento al respecto: la Agenda de Buen Gobierno (ABG). El sexenio 2006-2012 ve nacer el boom del GE en la administración pública federal. Se actualiza Compranet, crea el Manual de Aplicación General de TIC (MAAGTICSI) para uniformizar los procesos tecnológicos de todas las dependencias, aumenta el número de sitios .gob, lanza el esquema de interoperabilidad, datos abiertos, y, por supuesto, las instituciones y los funcionarios hicieron su aparición en redes sociales como Facebook, Twitter y You Tube con el objetivo de difundir sus acciones mientras se acercaban a los ciudadanos. En el sexenio 2013-2018, el GE es incluido en el Plan Nacional de Desarrollo y fue situado dentro de la línea de acción para un Gobierno Cercano y Moderno, consolidando su ejecución a partir de la Estrategia Digital Nacional (EDN) (figura 2).

Cronológicamente, el gobierno electrónico sienta las bases del gobierno abierto en los tres niveles de gobierno: municipal, estatal y federal; de ellos, es este último quien más ha aprovechado el GE. En México, los pilares fundamentales del gobierno abierto: colaboración, participación ciudadana y transparencia son novedosos y han fortalecido la escena nacional (tabla 2). Por ejemplo, el pilar de colaboración toma forma en la Ley de Asociaciones Público Privadas (2012) al establecer el marco normativo para que los sectores público y privado participen en proyectos de interés social. 
FIGURA 2. DESARROLLO DEL GOBIERNO ELECTRÓNICO EN MÉXICO

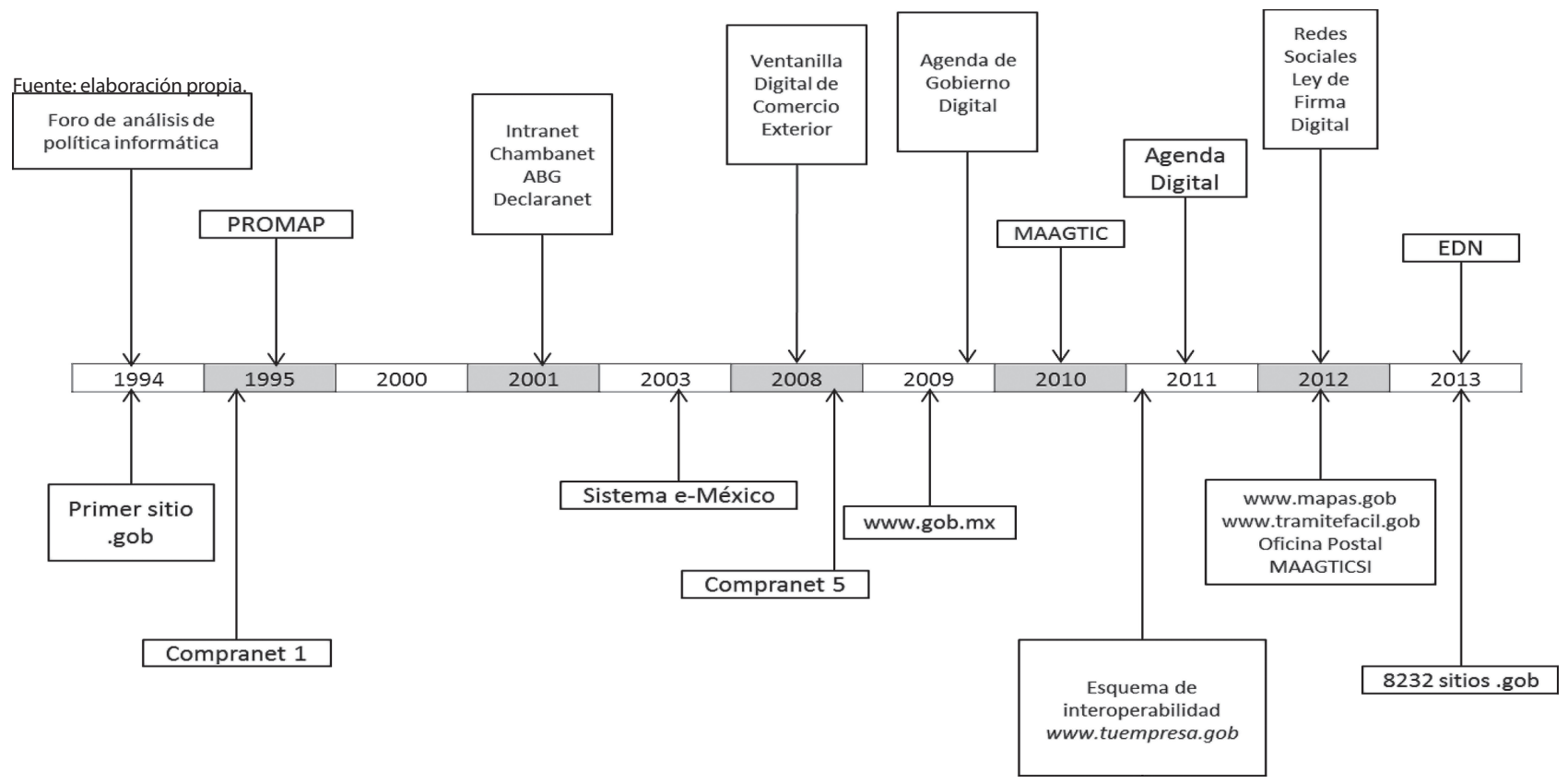

TABLA 2. PILARES DEL GOBIERNO ABIERTO Y HERRAMIENTAS DISPONIBLES EN MÉXICO

\begin{tabular}{|c|c|}
\hline $\begin{array}{c}\text { Pilar del } \\
\text { gobierno abierto }\end{array}$ & Herramienta disponible \\
\hline Transparencia & $\begin{array}{l}\text { - Ley General de Transparencia y } \\
\text { Acceso a la Información Pública } \\
\text { Gubernamental } \\
\text { - Portales de transparencia foca- } \\
\text { lizada } \\
\text { - Portales de visualización y da- } \\
\text { tos abiertos }\end{array}$ \\
\hline Participación & $\begin{array}{l}\text { - Ley Federal de Fomento a las } \\
\text { Actividades Realizadas por Or- } \\
\text { ganizaciones de la Sociedad } \\
\text { Civil, Códigos Electorales, } \\
\text { - Elecciones políticas, consultas } \\
\text { públicas, encuestas, sitios web }\end{array}$ \\
\hline Colaboración & $\begin{array}{l}\text { - Ley federal de Asociaciones } \\
\text { Público Privadas }\end{array}$ \\
\hline
\end{tabular}

Fuente: elaboración propia.
Si bien el pilar de participación ciudadana carece de mecanismos legales que influyan en la revocación de mandatarios (plebiscito o referéndum), o en la normativa promulgada (consulta popular, revocación de mandato), nuestra legislación cuenta con elementos que abonan al tema. En estados como Oaxaca y Chiapas, donde se permite a la población regirse no solo por leyes sino también por usos y costumbres, existen las asambleas ciudadanas; en ellas, los ciudadanos tienen derecho a participar y decidir a nivel comunitario los asuntos que les afectan. De igual forma, la federación ha emitiendo la Ley Federal de Fomento a las Actividades Realizadas por Organizaciones de la Sociedad Civil, que reconoce el papel de la sociedad civil en el diseño de políticas públicas. 
En lo que respecta al pilar de transparencia, entendida como el derecho de acceso a la información, desde 1977 México elevó a rango constitucional la obligación de garantizar este derecho humano. Sin embargo, no fue sino hasta el año 2003 que se creó una Ley Federal en la materia, junto con una autoridad facultada para atenderla (Instituto Federal de Acceso a la Información y Protección de Datos - IFAI), posteriormente, en 2014, renombrado Instituto Nacional de Transparencia, Acceso a la Información y Protección de Datos Personales (INAI). Sin lugar a dudas las TIC, y por ende el GE, han contribuido a consolidar este derecho en nuestro país.

De acuerdo con datos de Sergio López (2009, p. 51), durante el primer año de actividades del entonces IFAI se recibieron 2.665 solicitudes de acceso a la información (vía telefónica y presencial). Desde entonces, los números han ido en aumento. A partir de la reforma de 2007 y con la creación del sistema de portales de acceso a la información, el IFAI recibió 19.044 solicitudes de acceso, es decir, que de 2003 al 2007 la demanda de información aumentó en más del $700 \%$. Lo que es más, de acuerdo con el informe de labores del INAI, en 2016 se presentaron 1 millón 230 mil 813 solicitudes de acceso a la información, lo que representa un incremento de más de 5.000 veces respecto al primer año. Estos resultados demuestran, por una parte, el fuerte interés de los mexicanos por conocer el actuar del Gobierno y, por otro lado, que el derecho de acceso a la información es el pilar mejor consolidado en nuestro país (tabla 3).

\section{¿Y QUÉ PASA EN LOS MUNICIPIOS?}

El municipio es la institución más antigua que existe en México. Se considera como el primer municipio del país a la Villa Rica de la Vera Cruz, fundada en 1519 por el conquistador Hernán Cortés, es decir el municipio es anterior a las entidades y a la misma nación mexicana. Incluido constitucionalmente hasta 1917, con autonomía hacendaria en 1983 y reconocido como gobierno apenas en 1999, el municipio mexicano es el más joven de los tres órdenes de gobierno y, por tanto, el que más rezagos presenta en la aplicación de tecnología (GE), así como las más bajas tasas de transparencia, colaboración y participación ciudadana (GA).

De acuerdo con el Censo Nacional de Gobiernos Municipales y Delegacionales 2015 realizado por el INEGI, de 2.441 municipios solo

TABLA 3. NÚMERO DE SOLICITUDES DE INFORMACIÓN PÚBLICA 2003-2016

\begin{tabular}{|c|c|c|c|c|c|c|c|c|c|c|c|c|}
\hline \multirow{2}{*}{ Año } & \multicolumn{2}{|c|}{$2003-2012$} & \multicolumn{2}{|c|}{2013} & \multicolumn{2}{c|}{2014} & \multicolumn{2}{c|}{2015} & \multicolumn{2}{c|}{$\begin{array}{c}\text { Oct. 2015- } \\
\text { Sep. 2016 }\end{array}$} & \multicolumn{2}{c|}{ Total } \\
\cline { 2 - 15 } & Núm. & $\%$ & Núm. & $\%$ & Núm. & $\%$ & Núm. & $\%$ & Núm. & $\%$ & Núm. & $\%$ \\
\hline $\begin{array}{l}\text { Solicitudes } \\
\text { de informa- } \\
\text { ción pública }\end{array}$ & 711.671 & 82,1 & 109.406 & 74,4 & 114.727 & 79,9 & 120.813 & 78,6 & 202.365 & 83,3 & 1.230 .813 & 81,1 \\
\hline
\end{tabular}

Fuente: Informe de labores, INAI 2016. 
366 cuentan con algún ordenamiento sobre participación ciudadana. Las reglamentaciones son exiguas en los municipios; únicamente 531 han regulado la transparencia, apenas $143 \mathrm{el}$ combate a la corrupción y 366 la participación ciudadana. Estos datos manifiestan el contrasentido de trabajar el GA únicamente a nivel federal, puesto que se requiere de un esfuerzo unificado en los tres órdenes del Gobierno para disminuir los altos niveles de corrupción que aquejan al país.

El último estudio que abarcó el total de portales municipales de gobierno fue elaborado por la revista Política Digitalen el año 2010. Señala que de los 2.445 municipios que hay en México solo 1.204 cuentan con portal web, i.e., un $45 \%$ del total. El ranking incluye los componentes información y transparencia, y seńala que $36 \%$ de los municipios evaluados incumplen con el mismo. De igual forma, esta encuesta seńala que $39,84 \%$ de los portales revisados carecen de al menos un elemento de retroalimentación o participación ciudadana. Por tanto, es fundamental dotar a los municipios de sitios web informativos, interactivos y transaccionales, que incluyan elementos de participación y transparencia, es decir sitios verdaderamente 2.0. Estudios más recientes tienen como característica no haber considerado al total de municipios con portal web. En 2014, la consultoría Propulsar publicó el estudio Índice de Gobierno Digital Municipal, para el cual la muestra seleccionada fueron los 500 municipios más poblados cuya población en conjunto representa el $80 \%$ del país. Este estudio, además de considerar el portal web, tomó en cuenta otras herramientas como aplicaciones móviles y presencia en redes sociales.
Ahora bien, es claro que la creación de un portal va más allá de la simple inclusión de información un sitio web, es necesario que esta genere valor público para el ciudadano, ¿de qué sirve contar con información estática, poco entendible, inservible y sin valor público?, es necesario fomentar la reutilización de la información publicada; lo que implica que los datos publicados deben ser fiables, válidos y permitir a los ciudadanos hacer algo valioso e importante, y que dicho aporte se vea reflejado en la toma de decisiones (Harrison y Guerrero et al., 2011). En la siguiente sección se puntualizará sobre la generación de valor público.

Dos estudios del Instituto Mexicano de la Competitividad (IMCO) evalúan la importancia del valor público en la información. En el estudio Índice de Información Presupuestal Municipal (IIPM) de 2016, el municipio de Toluca, Estado de México, en materia de información presupuestal ocupa el lugar 156 en un universo de 453 municipios evaluados. Lo cual contrasta con el estudio Índice de Herramientas Electrónicas de Gobiernos Locales de 2015 realizado por el mismo IMCO, que ubicó a Toluca en el lugar número 12 de un total de 45 municipios y nueve delegaciones consideradas. Los datos nos revelan que si bien las TIC son importantes para el avance de la gestión pública, ellas no traerán consigo elementos de transparencia o de rendición de cuentas por el solo hecho de ser implementadas. Se ha documentado que "[aquellos gobiernos] que tienen buenos resultados controlando la corrupción en trámites y servicios no necesariamente tienen buenos resultados en transparencia” (Bohorquez, 2015). 
El ejemplo de Toluca muestra que la digitalización no necesariamente inhibe la corrupción, sino que es necesario reformular la gestión administrativa. Ello en vista de los múltiples casos de administraciones municipales en completa bancarrota o endeudamiento. Datos del Iıpм 2015 señalan que la deuda pública municipal ha crecido $83 \%$ desde el año 2007. En septiembre de 2015 la deuda se valuó en \$54 mil 621 millones de pesos y se distribuía entre 839 municipios del país, 20 de los cuales concentraron $45 \%$ del total. Tijuana aparece como el municipio más endeudado, con un monto de 2 mil 496 millones de pesos. Otros municipios con importantes problemas de deuda pública son: Monterrey, Nuevo León (2,146.1 mdp); Benito Juárez, Quintana Roo (1,365.9 mdp); Nuevo Laredo, Tamaulipas (1,114.7 mdp); León, Guanajuato (1,014.7 mdp); Mexicali, Baja California (950.2 mdp), y San Nicolás de los Garza, Nuevo León (901.8 mdp).

A pesar de estos resultados, la Federación Nacional de Municipios de México (fenamm) ha declarado que la deuda es baja y controlable; por su parte, la calificadora Moodys consideró que "la perspectiva del endeudamiento estatal y municipal permanece relativamente estable, $y$ que no existen indicios de un deterioro financiero en el sistema general" (Franco, 2012). Sin embargo, el panorama actual cuestiona el modelo financiero municipal tanto en la repartición como en los métodos de fiscalización y transparencia. Como lo señala Ignacio Alvarado, el modelo está rebasado ya que "no puede hablarse de verdadera fiscalización [...] por el hecho de que la federación entrega a los municipios 100 pesos [...] [ellos gastan 100 pesos y facturan esa cantidad]. Eso es tan solo un asunto contable. Lo que no se ha preguntado a los ayuntamientos ni a los gobiernos estatales es cómo están gastando ese dinero. Cuando uno [...] ve las disposiciones de gasto público, se encuentran cosas tan irracionales como que recursos del Ramo $33^{2}$ se destinan a la organización de ferias del pueblo o en la compra de vehículos" (Alvarado, 2011).

La legítima y esperada descentralización y autonomía financiera que suponía el fortalecimiento del municipio como institución de gobierno ha permitido continuar con viejas prácticas como el caciquismo, "la descentralización reduce la cantidad de monitoreo, dando a las oficinas locales más libertad para llevar a cabo actividades corruptas, particularmente en las ciudades rurales y pequeñas en México, donde los niveles de analfabetismo son más altos que en las grandes ciudades" (Nieto, 2011, p. 113). El caciquismo conlleva a la impunidad y esta permite que los presidentes municipales se crean inmunes y lleguen, incluso, a alardear de sus conductas irregulares.

Una muestra del caciquismo es la conducta del presidente municipal de San Blas, en el

\footnotetext{
2 El Ramo 33 - Aportaciones Federales para Entidades Federativas y Municipios es el mecanismo presupuestario diseñado para transferir a los estados y municipios recursos que les permitan fortalecer su capacidad de respuesta y atender demandas de gobierno en los rubros siguientes: Educación; Salud; Infraestructura básica; Fortalecimiento financiero y seguridad pública; Programas alimenticios y de asistencia social; e Infraestructura educativa. Con tales recursos, la federación apoya a los gobiernos locales que deben atender los reclamos que les plantea su población buscando, además, fortalecer los presupuestos de las entidades federativas y las regiones que conforman.
} 
estado de Nayarit, Hilario Ramírez Villanueva conocido como Layín, quien al aspirar por segunda vez a ocupar el cargo, declaro; "Han dicho que robé mucho dinero. Sí robé, pero poquito, porque no había dinero. Que le robé a la presidencia (municipal), sí le robé, sí le robé poquito, porque está bien pobre. Le di una rasuradita, nomás una rasuradita” (Carrillo, 2014). Tras estas declaraciones, la Auditoría Superior del Estado de Nayarit detecto en 2017, operaciones irregulares por 225 millones de pesos durante las gestiones de 2008-2011 y 2014-2017 (Rodríguez, 2017). De igual forma, el Órgano de Fiscalización Superior del estado de Nayarit señaló diversas irregularidades como que la página de internet no está actualizada conforme a lo dispuesto por la Ley General de Transparencia y concluye que en la administración de Layín existió una

\footnotetext{
...Afectación incorrecta de las partidas de gasto, control interno insuficiente, diferencia en alta de presupuesto aprobado, gastos improcedentes, no se elaboró el programa anual de adquisiciones, no se respeten los montos máximos para cada procedimiento de adquisición, pagos que no corresponden al ejercicio fiscal, retenciones pendientes de enterar, saldos correspondientes a ejercicios anteriores; errores y omisiones de la Información Financiera por $\$ 19,535,167.68$ diecinueve millones quinientos treinta y cinco mil ciento sesenta y siete pesos $68 / 100$ moneda nacional), que se integran por operaciones o
}

bienes no registrados o registrados errónea o extemporáneamente, diferencias entre registros administrativos contables y presupuestales y un monto observado como presunto dańo o perjuicio a la Hacienda Pública por $\$ 7,165,661.99$ (siete millones ciento sesenta y cinco mil seiscientos sesenta y un pesos 99/100 moneda nacional), que se refiere a: documentación comprobatoria que no reúne requisitos fiscales, faltantes de comprobación, gastos improcedentes, documentación comprobatoria sin justificación del gasto, $\mathrm{y}$ anticipos sin amortización (Órgano de Fiscalización Superior, 2010).

Actualmente, los enlaces de transparencia del municipio de San Blas se encuentran sin información ${ }^{3}$.

Al día de hoy, múltiples municipios en México tienen graves problemas de rezago tecnológico; magros sistemas de administración, personal poco capacitado para utilizarlos, deficientes controles, administraciones que aún operan archivos físicos y falta de conexiones a internet, entre otros aspectos. Lo que pone de manifiesto, una vez más, la urgencia de un cambio al actual modelo de operación, puesto que "las élites y los caciques locales han aprovechado la descentralización no solo para ganar más poder político y económico, sino también para ejercer la impunidad y la corrupción sin controles federales" (Nieto, 2011, p. 113).

En este contexto se abre una ventana de oportunidad ${ }^{4}$ para el gobierno electrónico y

3 http://sanblas.gob.mx/index.php/transparencia

4 De acuerdo con Mauricio Merino, una "Ventana de oportunidad" es un concepto que refiere momentos y condiciones de cambio en las agendas públicas, especialmente por factores coyunturales o no constantes del medio ambiente, aunque estos se relacionen con problemas de mucho tiempo. Véase, por ejemplo, la obra de John Kingdon, Agendas, Alternatives and Public Policies, Harper Collins, Nueva York, 1995. Para Kingdon, una "ventana” se abre cuando confluyen tres "arroyos" (streams), el del problema, el de las políticas y el de la política, esto es, cuando algo se fija públicamente como problema público y existen alternativas para implementar e incentivos para que los políticos implementen los cambios (Merino, 2015). 
gobierno abierto a efecto de combatir el círculo vicioso que limita el desarrollo municipal (Olmedo, 2014, p. 14). Es necesario llevar a los municipios formas de apertura gubernamental mediante el uso de tecnologías de la información. Crear una especie de municipio 2.0 que permita la generación de espacios de interacción robustos, así como abrir canales de comunicación con los ciudadanos, considerando el diseño de políticas públicas de infraestructura y alfabetización digital.

\section{APORTES DEL GOBIERNO ELECTRÓNICO Y EL GOBIERNO ABIERTO A LOS MUNICIPIOS. GENERACIÓN DE VALOR PÚBLICO}

Los gobiernos locales tienen en el gobierno electrónico y gobierno abierto una ventana de oportunidad para su fortalecimiento. Legislativamente, la Ley General de Transparencia y Acceso a la Información Pública Gubernamental, del 04 de mayo de 2015, establece en sus artículos 42, fracción xx, y 59, la obligación de fomentar los principios de gobierno abierto, transparencia, rendición de cuentas, participación ciudadana, accesibilidad e innovación tecnológica a nivel federal, estatal y municipal, utilizando políticas y mecanismos de apertura gubernamental (figura 3).

Un aspecto importante de la ley es que por primera vez, en la historia democrática del país, se obliga a los municipios a incluir mecanismos de transparencia como parte de sus atribuciones pues hasta antes del 2015 dichas obligaciones se limitaban al ámbito federal. Tal disposición legislativa conlleva la necesidad de implementar, o mejorar en su caso, la calidad de las herramientas tecnológicas utilizadas en la administración pública que les exige trabajar en el marco de los principios del gobierno abierto.

FIGURA 3. JERARQUÍA DE LAS LEYES EN MÉXICO Y LAS REFERENTES A GOBIERNO ELECTRÓNICO Y GOBIERNO ABIERTO

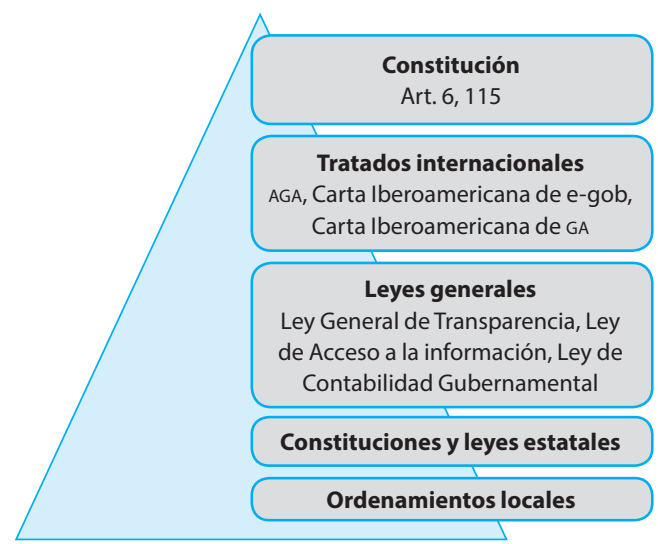

Fuente: elaboración propia.

A continuación se desarrollará el contexto del modelo evolutivo, mencionado en el primer apartado de este trabajo, trasladándolo al ámbito municipal y a la luz de las obligaciones de la Ley General de Transparencia y Acceso a la Información Pública Gubernamental, la cual señala que la información deberá ser puesta a disposición del público, manteniéndola actualizada y accesible en medios electrónicos, según corresponda, de acuerdo con las facultades, atribuciones, funciones y objeto social de los sujetos obligados.

La primera etapa o de presencia del modelo evolutivo, incluye únicamente imágenes, textos breves, y poca o nula información de contacto. Es poco probable que un sitio web de esta naturaleza pueda ser considerado GE, $y$ en definitiva es un aporte mínimo o nulo al GA. 
En la etapa de información, o segunda etapa, las herramientas de gobierno electrónico, ya sea sitio web, aplicación móvil o redes sociales, se enriquecen con documentos, avisos, eventos, directorios. Se habla, aunque en forma limitada, de transparencia proactiva, en la cual "algunos portales usan estructuras tradicionales como directorios o menús, otros permiten a los usuarios buscar información usando un buscador y, más recientemente, algunos de ellos utilizan herramientas multimedia como video, audio o en línea” (Sandoval y Gil, 2012, p. 74). En este caso se podría, por ejemplo, cumplir con la información que las leyes de transparencia obligan a publicar ${ }^{5}$.

De acuerdo con la Encuesta Nacional de Acceso a la Información Pública y Protección de Datos Personales 2016, de Inegi, el 44\% de la población mayor de 18 años utiliza como principal medio para buscar y acceder a la información pública las páginas de internet gubernamentales, mientras que un $20 \%$ de los mexicanos acude directamente a la sede del gobierno de su interés.

En la tercera etapa o de interacción, se esperan herramientas más completas, seguras, donde la información tenga valor para el usuario, "leyes, publicaciones gubernamentales, reportes que se pueden obtener directamente de los sitios y transmitirse a sus computadoras" (Gil, 2014, p. 6). De igual forma, se esperan canales de comunicación, como correos electrónicos de los funcionarios, quienes deberán contar con un plan de trabajo que analice la información recibida de los ciudadanos, fomentando así la colaboración. Idealmente, a nivel municipal la información debería ser más tangible ya que es en ese nivel "desde donde los ciudadanos podrán contar con las herramientas necesarias para ejercer su legítimo derecho a participar, contribuir y colaborar en la consecución del bien colectivo" (oEA, 2015, p. 24).

En la etapa de transacción, los sitios web y las aplicaciones móviles se han erigido como las herramientas más adecuadas para que los ciudadanos realicen el pago de impuestos, multas, o para que las empresas realicen trámites de apertura. Por su parte, la etapa de integración considera uno de los compromisos de México en la Alianza por el Gobierno: Tu gobierno en un solo sitio. Este sitio web busca simplificar los servicios de gobierno, haciéndolos más sencillos para el ciudadano. Ambas etapas implican "[elevar] los niveles de confianza de la ciudadanía en las instituciones políticas, [potenciar] la participación y el compromiso cívico, y [mejorar] la calidad, eficacia y eficiencia de los gobiernos y sus administraciones públicas, bajo principios de equidad, integridad y transparencia” (Dassen y Cruz, 2012, p. 60).

Las herramientas de esta etapa fungen como una alternativa para mejorar los procesos de recaudación fiscal en los municipios, fortaleciendo así su autonomía. El municipio de Hermosillo (que alberga uno de los mejores portales de sitio web, de acuerdo con el

\footnotetext{
5 La información obligada a publicar se encuentra señalada en los artículos 70 al 80 de la Ley General de Transparencia y Acceso a la Información e incluye: estructura orgánica de los sujetos obligados, marco normativo aplicable, facultades y atribuciones, directorio de servidores públicos, remuneración mensual por puesto, nombre, domicilio legal y dirección electrónica de la Unidad de Enlace y Comité de Información, programa Operativo Anual, Servicios y trámites que ofrecen, presupuesto, resultados definitivos de las auditorías concluidas.
} 
ranking de Política Digital de 2010 y el del IMCO de 2015), ha marcado una tendencia favorable por el uso de las Tic en funciones de recaudación. Según los informes de gobierno, se reportó que en el trienio 2009-2012 se realizaron entre 1.100 y 1.400 transacciones por mes y se atendieron más de 330.000 peticiones en línea, en las diversas áreas de la Administración Pública. Gracias, al Catastro Digital, el municipio recaudó $\$ 6^{\prime} 672,831.10$ pesos en tan solo 4 meses. El actual gobierno 20152018 no desglosa tanto los ingresos recibidos por vía electrónica, pero sí resalta el papel de las herramientas de GE, en la facilitación de las labores de recaudación, fortaleciendo su hacienda propia, a contrasentido de la mayoría de los municipios mexicanos que dependen financieramente de las transferencias estatales y federales.

Otro caso relevante es la tendencia marcada por el municipio de Mérida, que en 2010 implementó el programa Predial Móvil, mediante el cual se habilitó el pago de predial desde un dispositivo Blackberry y logró recaudar 5,14 millones de pesos, y en 2015, con la opción carrito electrónico, recaudó 175,8 mdp., aumento considerable respecto de años anteriores al uso de herramientas electrónicas, como 2008 cuando se utilizó la estrategia de exhortos, logrando una recaudación de $\$ 957.000$ pesos.

Finalmente, la etapa de gobierno abierto incluye herramientas que permiten la participación, colaboración y transparencia. Se considera la evolución más alta del gobierno electrónico y representa "un cambio en la tradicional relación entre gobierno y ciudadanos, creando una nueva interfaz virtual" (Wong y Welch, 2004, p. 275) Aquí las herramientas de la cuarta etapa se constituyen en canales de apertura gubernamental al complementarse con factores clave como información y datos, organización y administración, marco legal y regulatorio, compatibilidad de sistemas de información, y manejo de conflictos organizacionales (Gil y Pardo, 2005).

Esta etapa trasciende la transparencia focalizada y posibilita la transparencia colaborativa al contar con información reutilizable integrando sitios de datos abiertos, portales de visualización o apps cívicas, no solo por parte del Gobierno, sino al fomentar procesos de innovación ciudadana "que se basan en aprovechar los recursos y la creatividad de las redes y comunidades externas (incluidas las redes ciudadanas, así como las redes de organizaciones sin fines de lucro y empresas privadas) para aumentar o mejorar la velocidad de innovación" (Nambisan, 2005, p. 11). De manera paulatina y con diversos grados de intensidad, las herramientas de gobierno electrónico y gobierno abierto comienzan a formar parte de los programas de trabajo de las administraciones municipales (tabla 4).

\section{ASIGNATURA PENDIENTE}

Cuando se habla de GE, no se puede ignorar el factor brecha digital, la cual menciona Averweg (2009), y existe tanto entre países como al interior de estos, y la llamada "brecha doméstica". La ONU (2012) identifica distintas formas de entender la brecha digital: 
TABLA 4. DISPONIBILIDAD DE GE Y GA EN MUNICIPIOS DE MÉXICO

\begin{tabular}{|c|c|c|}
\hline $\begin{array}{l}\text { Pilar del gobierno } \\
\text { abierto }\end{array}$ & Herramienta disponible & $\begin{array}{l}\text { Municipios que cuentan con algún } \\
\text { elemento relacionado }\end{array}$ \\
\hline \multirow[t]{3}{*}{ Transparencia } & $\begin{array}{l}\text { Ley General deTransparencia y Acceso } \\
\text { a la Información Pública Guberna- } \\
\text { mental }\end{array}$ & $\begin{array}{l}320 \text { con disposición de archivos } \\
534 \text { reglamento Transparencia y acceso a la información } \\
569 \text { con un responsable de las solicitudes de información. } \\
684 \text { con comisiones de transparencia }\end{array}$ \\
\hline & - Portales de transparencia focalizada & $\begin{array}{l}\text { Los municipios tiene como obligación hacer uso de la } \\
\text { Plataforma Nacional de Transparencia }\end{array}$ \\
\hline & $\begin{array}{l}\text { Portales de visualización y datos } \\
\text { abiertos }\end{array}$ & \\
\hline \multirow[t]{2}{*}{ Participación } & $\begin{array}{l}\text { Ley Federal de Fomento a las Activida- } \\
\text { des Realizadas por Organizaciones de } \\
\text { la Sociedad Civil, Códigos Electorales }\end{array}$ & $\begin{array}{l}366 \text { con reglamentación sobre participación ciudadana. } \\
771 \text { organizaciones ciudadanas o sociales } \\
138 \text { organizaciones no gubernamentales (ONG) } \\
884 \text { con comisiones de participación ciudadana }\end{array}$ \\
\hline & $\begin{array}{l}\text { Elecciones políticas, consultas públi- } \\
\text { cas, encuestas, sitios web }\end{array}$ & $\begin{array}{l}\text { Depende de cada entidad y municipio determinar los } \\
\text { mecanismos de participación }\end{array}$ \\
\hline \multirow[t]{2}{*}{ Colaboración } & $\begin{array}{l}\text { Tequios, Faenas (acciones de colabo- } \\
\text { ración vecinal establecidas en leyes } \\
\text { orgánicas municipales) }\end{array}$ & $\begin{array}{l}1358 \text { con organizaciones vecinales o de obra } \\
436 \text { con tequio }\end{array}$ \\
\hline & $\begin{array}{l}\text { Ley Federal de Asociaciones Público- } \\
\text { Privadas }\end{array}$ & $\begin{array}{l}146 \text { organizaciones gremiales y clubes de servicios } \\
127 \text { organizaciones de beneficencia }\end{array}$ \\
\hline
\end{tabular}

Fuente: elaboración propia con datos de: Censo Nacional de Gobiernos Municipales y Delegacionales, 2014; Censo Nacional de Gobiernos Municipales y Delegacionales, 2015; Encuesta nacional de gobierno, seguridad pública y justicia municipal, 2009.

Factores socioeconómicos: municipios en situación de pobreza y marginación.

- Infraestructura: municipios que por su ubicación geográfica o financiera no están dotados de infraestructura u operadores de telecomunicación.

- Habilidades y destrezas: municipios con personal capacitado para utilizar las TIC. Apoyo al sistema de gobierno como factor para participar en la vida pública electrónicamente: hay municipios que se manejan por sistemas normativos internos (como los que existen en estados como Oaxaca y Chiapas), los cuales están en conflicto constante.
Hay que decir que no existe obligación jurídica de los municipios para contar con página de internet. Leyes como la de Contabilidad Gubernamental o la Ley General de Transparencia no obligan a los municipios con población menor a 70 mil habitantes a contar con una página web en la que se publique información. Sin embargo, nos los exime de cumplir con obligaciones de transparencia y rendición de cuentas. Según el imco (Suárez, 2015) algunos municipios, ante la carencia de medios digitales, aún elaboran sus presupuestos a mano, lo cual genera que objetivos como la transparencia, la rendición de cuentas, el combate a la corrupción y la homologación 
contable sean virtualmente imposibles (Pardinas y Granados, 2010).

En vista de la brecha digital que existe en el país es difícil esperar que todos los municipios cuenten con una página web, empero, no se puede ser indulgente ante la omisión de responsabilidades como la transparencia y la rendición de cuentas. Tradicionalmente, los municipios cuentan con medios de difusión, como gacetas impresas, radios, medios audiovisuales o el periódico mural.

Una forma de repensar el gobierno abierto en los municipios que carecen de acceso a herramientas digitales es plantear los atributos de transparencia, rendición de cuentas y colaboración sin el elemento digital. La desvinculación permite conceptualizar el elemento como una forma de gobernanza, llevándolo más allá de una herramienta de gestión. Esa es la aproximación que UNPAN/UNDESA realiza sobre una evaluación del gobierno electrónico en países africanos. La evaluación recomienda, entre otros mecanismos, generar procesos de interoperabilidad con equipos móviles (Hafkin, 2009, p. 14). Aunque de acuerdo con Chango y Ngubule, la implementación de un sistema tecnológico debe considerar la realidad del lugar en el que será implementado (pp. 11-12).

En México, las organizaciones de la sociedad civil están ayudando a cerrar la brecha digital y empoderar a los ciudadanos al ofrecer talleres que les ayuden a conocer cómo ejercer el derecho de acceso a la información para conseguir, por ejemplo, médico y medicinas en comunidades rurales como fue el caso de la localidad de Lázaro Cárdenas, Palenque, Chiapas que recibió capacitación por parte de Artículo 19 (Roldán, 2017).
Si bien para contar con un gobierno abierto el factor tecnológico no es indispensable, sí es relevante ya que facilita el cumplimiento de ciertas obligaciones. Esto incluso nos permite conocer la madurez de la sociedad que nos conduce a una "concepción de la acción estatal y de la sociedad en su conjunto, donde la información no sea vista como algo exclusivo del Gobierno, buscando aprovechar las capacidades que surgen de la sociedad civil" (Hernández, Gandur y Najles, 2014, p. 8).

\section{CONCLUSIONES}

México ha fomentado el uso de las TIC en los procesos de modernización de la administración pública con diferentes "niveles" de asimilación de TIC en los procesos de gestión pública. Lo anterior ha supuesto un progreso desigual entre los distintos niveles de gobierno, pues mientras el Gobierno federal avanzó notablemente en la implementación de herramientas de gobierno electrónico como es el caso de portales, aplicaciones móviles, redes sociales, por citar algunos, y se aprecia el auge de instrumentos del gobierno abierto: datos abiertos y portales de transparencia entre otros elementos, los gobiernos a nivel estatal y municipal se encuentran todavía en un proceso inicial de desarrollo e implementación de dichas herramientas.

De lo anterior se desprende la necesidad y de impulsar el gobierno electrónico y el gobierno abierto en la administración pública local, adecuándolo a las circunstancias locales. La introducción de elementos del GE y el GA permitirán, muy probablemente, abonar 
a una mejor gestión de los gobiernos locales. Por una parte, las herramientas TIC permiten a los municipios abrir canales de comunicación y acercar el Gobierno a los ciudadanos, idealmente las TIC podrían ayudar a identificar de manera más oportuna la solución a problemas gubernamentales al contar con la participación ciudadana. De igual forma, a través de la tecnología se espera mejorar la rendición de cuentas $\mathrm{y}$ transparencia, un aspecto fundamental si se quiere lograr el cumplimiento de los acuerdos internacionales y los grupos de trabajo a los que México está suscrito. De esta manera las bases de la Federación, como lo proponemos en este artículo, podrían convertirse en elementos clave para el desarrollo de soluciones y mejoras en la administración pública, es decir pensar global y actuar local.

La unidad de estudio de este trabajo, los municipios, son un interesante laboratorio para comprobar este argumento, dadas sus características de proximidad a la población, que permite un diálogo y colaboración más cercana y directa; la actividad de prestación de servicios, y las obligaciones jurídicas y hacendarias. A esto podemos sumar las complejidades y heterogeneidad que cada municipio representa, lo cual implica que no hay un camino único para la utilización de estas herramientas, algunos estarán en condiciones de sacarles el mayor provecho, y otros tendrán que construir las bases de uso.

Si bien los beneficios del gobierno abierto y el gobierno electrónico parecen incuestionables, vale la pena contextualizar su implementación de acuerdo con las particularidades de cada región. Debemos, por tanto, ajustar nuestras expectativas respecto al GE y el GA puesto que su sola implementación no resolverá todos los problemas que enfrenta el país, ni siquiera en términos de corrupción, muy probablemente.

Es cierto que en la medida de sus capacidades, los municipios han incorporado herramientas de gobierno electrónico con fines de gestión. No obstante, de forma sistémica el país adolece del uso de la tecnología como una herramienta de desarrollo, gestión pública o acercamiento ciudadano. En particular, los gobiernos municipales tienen poco o nulo uso de las TIC al desaprovecharlas como herramienta de contacto ciudadano. Si bien desde la década del 2000 múltiples herramientas han sido puestas en línea para tratar de simplificar los trámites administrativos, disminuir los niveles de burocratización y los costos de la administración pública, aún hay múltiples recursos que deben solventarse antes de considerar acabada la tarea del GE y GA.

\section{REFERENCIAS}

Aguilar Villanueva, L. F. (2009). Gobernanza y Gestión Pública. México: Fondo de Cultura Económica. Alianza para el Gobierno Abierto (2017). Plan de Accion 2016- 2018. En Tercer Plan de Acción Nacional de México en la Alianza para el Gobierno Abierto. Recuperado de http://gobabiertomx. org/wp-content/uploads/2016/09/Plan-deAcci\%C3\%B3n-2016-2018.pdf

Alvarado, I. (2011). Enfrentan más de $80 \%$ alcaldes crisis por deudas. El Universial. Recuperado de http://www.eluniversal.com.mx/notas/751515. html 
Averweg, U. R. (2009). E-Government and Digital Divide in. Developing Countries. UsA: Mehdi Khosrow-Pour.

Bohorquez Eduardo, G. I. (2015). Este país. Tendencias y opiniones. En Factofilia: más transparencia no es igual a menos corrupción. Recuperado de http://www.estepais.com/articulo. php?id=291\&t=factofilia-mas-transparenciano-es-igual-a-menos-corrupcion

Carrillo, G. (2014). Exalcalde: sí robé poquito; "ojalá hubieran estado los 150 millones". Excelsior Recuperado de http://www.excelsior.com.mx/ nacional/2014/06/09/963987

Cordella, A. (2007). E-government: towards the ebureaucratic form? Journal of Information Technology, 3 (22), 265-274.

Criado, J. I. (2009). Entre sueños utópicos y visiones pesimistas. Internet y las tecnologías de la información y la comunicación en la modernización de las administraciones públicas. Madrid: INAP.

Cruz-Meléndez, C. (2015). Gobierno Electrónico para lograr el Gobierno Abierto. En CLAD (p. 22). Lima: CLAD.

Dassen, N. y Cruz, J. (2012). Gobierno abierto y transparencia focalizada. Tendencias y desafios para América Latina y el Caribe. Washington, D.C.: BID.

Franco, F. (2012). Solo $10 \%$ de la deuda municipal tiene aval. Recuperado de http://eleconomista. com.mx/finanzas-publicas/2012/10/10/solo10-deuda-municipal-tiene-aval

Gil-García, J. R. (2014). Propuesta de evaluación para portales de gobierno. Revista Chilena de Administración, 83-122.

Gil-García, J. R. y Luna-Reyes, L. F. (2008). Una Breve introducción al gobierno electrónico: definición, aplicaciones y etapas. Revista de Administración Pública , 49-72.
Gil-García, J. R. y Martínez-Moyano, I. J. (2007). Understanding the evolution of e-government: The influence of systems of rules on public sector dynamics. Government Information Quarterly (24), 266-290.

Gil-Garcia, J. R. y Pardo, T. (2005). E-government succes factors: Mapping practical tools to theoretical foundations. Government Information Quartely (22), 187-216.

Gore, A. (1999). Details emerge on e-government directive. Recuperado de http://fcw.com/articles/1999/12/20/details-emerge-on-egovernment-directive.aspx

Hafkin, N. J. (2009). Women in Global Science and Technology. En Undesa/unPan (ed.) E-government in Africa: An Overview of Progress Made and Challenges Ahead. Recuperado de http://wisat. org/wp-content/uploads/unpan034002.pdf

Harrison, T., Guerrero, S. et al. (2011). Open Government and E-Government: Democratic Challenges from a Public Value Perspective. Recuperado de https://www.ctg.albany.edu/publications/journals/dgo2011_opengov

Hernández, J., Gandur, M. P. y Najles, J. (2014). Gobierno municipal abierto en América Latina: de la proximidad administrativa a la acción colaborativa. Washington: OEA.

Hevia de la Jara, F. (2013). La participación ciudadana y la rendición social de cuentas en México. En G. D. (ed). Rendición de cuentas social en México. Evaluación y control desde la sociedad civil (pp. 37-50). México: Gobierno del Estado de Oaxaca.

Linares, J. (2010). e-Gobierno y Gobierno Abierto. Recuperado de http://www.suboletin.com/ contentsoea/docs/Boletin_55/Principal55.htm

López, S. (2009). El acceso a la información como un derecho fundamental: la reforma al articulo $6^{\circ}$ de la Constitución mexicana. México: IFAI. 
Mejía, N. (2013). Balance y perspectivas del desarrollo municipal. México, D.F.: Instituto Nacional de Administración Pública, A.C.

Merino, M. (2015). México la batalla contra la corrupción: (Una reseña sobre las reformas en curso a favor de la transparencia y en contra de la corrupción). México: Wilson Center, Mexico Institute.

Nambisan, S. (2005). Transforming Government Through Collaborative Innovation (vol. 11). Washington, D.C.: IвM Center for The Business of Government.

Nieto, N. (2011). Corruption, Decentralisation and caciquismo in Mexico in the last decade. SudHistoria (3), 102-120.

oeA (2015). Marco conceptual del Gobierno Abierto. Washington: OEA.

Olmedo, R. (2014). La siguiente y urgente reforma municipal. Otra administración pública municipal es posible. Revista IAPEM (88), 11-24.

Órgano de Fiscalización Superior (2010). Órgano de Fiscalización Superior del Estado de Nayarit. En Informe del resultado de la fiscalización de la cuenta pública 2010. Recuperado de http://www. ofsnayarit.gob.mx/new/informes.php?Y=2010

Ozlak, O. (2013). Gobierno abierto: hacia un nuevo paradigma de gestión pública. Washington: OEA.

Pardinas, J. y Granados, E. (2010). El municipio, ¿la institución de la opacidad? México: CIDE.

Pardo, M. D. (2007). La gerencialización de la administración pública. Foro Internacional, XLVll (4), 895-925.

Pérez Zúñiga, R., Camacho Castillo, O., Mena Hernández, E. y Arroyo Cervantes, G. (2015-2016). Análisis general del gobierno electrónico en México. Pakaat: Revista de Tecnología y Sociedad (9).

Popper, K. R. (1962). The Open Society and its Enemies. London: Routledge \& Keagan Paul.
Pratts, J. (2005). De la burocracia al management, del managementa la gobernanza. Madrid: INAP.

Ramírez-Alujas, Á. (2011). Gobierno abierto y modernización de la Gestión pública: tendencias actuales y el (inevitable) camino que viene. Reflexiones seminales. Enfoques, IX (15), 99-125.

Ramírez-Alujas, Á. V. (2012). Gobierno abierto es la respuesta: ¡cuál era la pregunta? Más Poder Local, 14-22.

Ramírez-Alujas, Á. y Dassen, N. (2014). Winds of Change: The Progress of Open Government Policymaking in Latin America and the Caribbean. Inter-American Development Bank.

Ríos, V., Enríquez, A. y Espejel, O. Y. (2015). Estado de derecho. México DF: México ¿cómo vamos?

Rodríguez, E. D. (2017). Layin, el alcalde que no roba tan poquito. El Universal. Recuperado de http:// www.eluniversal.com.mx/articulo/periodismode-investigacion/2017/03/21/layin-el-alcaldeque-no-roba-tan-poquito.

Roldán, N. (2017). Una solicitud de información permitió a una comunidad de Chiapas conseguir médico y medicinas. Animal político. Recuperado de http://www.animalpolitico.com/2017/03/ comunidad-chiapas-medico-medicinas/

Sandoval, R. (2013). La larga marcha del Gobierno Abierto. Teoría, medición y futuro. México: INAP.

Sandoval, R. y Gil-García, J. R. (2012). Are government internet portals evolving towards more interaction, participation, and collaboration? Revisiting the rhetoric of e-government among municipalities. Government Information Quarterly, 72-81.

Streib, G. D. y Willoughby, K. G. (2002). Local governments becoming e-government: Getting the sizzle, avoiding the fizzle. En Frederickson, H. G. y Nalbandian, J. The Future of Local Government Administration (p. 263). International City/Council Management Association.

OPERA, $N^{\circ} 21 \cdot J u l i o-D i c i e m b r e ~ 2017 \cdot p p .55-77$ 
Suárez, R. (2015). La opacidad municipal. Recuperado de http://imco.org.mx/politica_buen_gobierno/ la-opacidad-municipal/

Tkacz, N. (2012). From open source to open government: a critique of open politics. Ephemera. Theory \& politics in organization, 12(4), 386-405. Recuperado de www.ephemeraweb.org

Tkacz, N. (2013). Aeon Magazine. Recuperado de https://aeon.co/essays/bazaar-the-rise-and-riseof-open-source-politics
United Nations (2012). E-Government Survey 2012. New York: ONU.

Uvalle, R. (2009). Condiciones, procesos y tendencias de la administración pública contemporánea. Convergencia (49), 73-102.

Wong, W. y Welch, E. (2004). Does e-government promote accountability? A comparative analysis of website openness and government accountability. Governance, 275-297. 